Chapter 19

\title{
Novel Antioxidant Therapy Against Myocardial Ischemia-Reperfusion Injury During Percutaneous Coronary Angioplasty
}

\author{
Pablo Parra and Ramón Rodrigo
}

Additional information is available at the end of the chapter

http://dx.doi.org/10.5772/63658

\begin{abstract}
Acute myocardial infarction (AMI) is the leading cause of mortality worldwide. Major advances in the treatment have included coronary interventions, such as systemic thrombolysis and percutaneous coronary angioplasty (PCA). These procedures have been aimed to recover the blood flow in the cardiac zones affected by the occlusion of a branch of the coronary artery. However, damage is generated in the heart tissue known as myocardial reperfusion injury, an event associated with increased oxidative stress. Reactive oxygen species (ROS) are able to trigger cell death pathways, and myocardial structural and functional impairment. Studies on animal models of AMI suggest that lethal reperfusion accounts for up to $50 \%$ of the final size of a myocardial infarct, a part of the damage likely to be prevented. Although a number of strategies have been aimed to ameliorate lethal reperfusion injury, up to date the beneficial effects in clinical settings remain elusive. The accumulated body of evidence suggests that redox balance is a crucial determinant of ischemia-reperfusion injury, with clear mechanistic insights into pharmacological approaches. This chapter presents the molecular basis for a novel cardioprotection of patients with AMI subjected to PCA, based on a reinforcement of the antioxidant system.
\end{abstract}

Keywords: acute myocardial infarction, ischemia-reperfusion, oxidative stress, antioxidant therapy, coronary angioplasty

\section{Introduction}

According to the World Health Organization, a total of 56 million deaths occurred worldwide during 2012 and 17.5 million (31.25\%) were due to cardiovascular diseases, still the principal 
cause of death by noncommunicable diseases. In addition, deaths due to ischemic heart disease (IHD) in 2012 were estimated as 7.4 million (13.2\%), remaining as the leading cause of death over the past decade [1,2], with a considerable social impact due to mortality, morbidity, loss of quality of life and high economic cost. In IHD, severe and prolonged myocardial ischemic events occur through thrombotic complications from atherosclerotic plaques in pericardial coronary arteries, leading to cardiomyocyte death. The latter becomes more significant when ischemia is caused by complete coronary occlusion, generating an acute myocardial infarction (AMI) where the coronary microcirculation is significantly reduced, affecting most of the left ventricular wall thickness together with structural and functional impairments, scarring and adverse remodeling $[3,4]$. The most effective therapeutic intervention for reducing the size of a myocardial infarct and improving the clinical outcome is timely and effective restoring of coronary flow using either thrombolytic therapy or percutaneous coronary angioplasty (PCA), but this process can itself induce further viable cardiomyocyte death and increased infarct size, a phenomenon known as myocardial reperfusion injury (MRI), thus reducing the beneficial effects. The MRI causes four types of cardiac dysfunction, the first two being reversible and the others irreversible: (i) reperfusioninduced arrhythmias; (ii) myocardial stunning; (iii) microvascular obstruction or no-reflow phenomenon; and (iv) lethal myocardial reperfusion injury (LMRI). LMRI is the most important because may account for up to $50 \%$ of the myocardial infarct (MI) final size as shown in both experimental ischemia-reperfusion (I/R) models and patients with ST-segment elevation MI applying therapeutic interventions solely at the onset of myocardial reperfusion $[5,6]$. In addition, several experimental studies have shown the important role of oxidative stress in MRI and it has been postulated as a therapeutic target for cardioprotection [7-13]. However, the clinical trials have shown mixed results with no clear confirmation of the beneficial effects of exogenous antioxidant therapy at the onset of myocardial revascularization, possibly due to differences in the design and methodology [14]. Next, we describe the pathophysiological mechanisms involved in MRI and the molecular basis for a novel cardioprotective treatment of patients with AMI subjected to PCA, based on a reinforcement of the antioxidant system.

\section{Oxidative stress and the pathophysiology of myocardial ischemia- reperfusion injury}

Occlusion of a coronary artery decreases blood flow to myocardial tissue causing a state of prolonged ischemia. The lack of oxygen and nutrients triggers a series of abrupt metabolic and biochemical changes within the cardiomyocyte that lead to several mechanisms of cell death, which are enhanced in the reperfusion (Figure 1).

During acute myocardial ischemia, the absence of oxygen in the mitochondrial electron transport chain (mETC) causes a drop in the production of adenosine triphosphate (ATP), and the glycolytic pathway generates a shift to anaerobic respiration with intracellular accumulation of lactic acid $[9,15]$. In addition, the Krebs cycle stops and $\mathrm{CO}_{2}$ cannot be eliminated from the extracellular space due to blood flow arrest. Therefore, a decrease in the intracellular $\mathrm{pH}$ 
$(<7.0)$ occurs, which increases the $\mathrm{Na}^{+}$influx through the $\mathrm{Na}^{+} / \mathrm{H}^{+}$exchanger, while the ATP depletion stops $\mathrm{Na}^{+}$efflux through $\mathrm{Na}^{+} / \mathrm{K}^{+}$-ATPase. This intracellular $\mathrm{Na}^{+}$accumulation activates $\mathrm{Na}^{+} / \mathrm{Ca}^{2+}$ exchangers in the reverse direction leading to cytosolic $\mathrm{Ca}^{2+}$ overload [16], where the sarcoplasmic reticulum is unable of uptaking $\mathrm{Ca}^{2+}$ from the cytosol because sarco(endo)plasmic reticulum $\mathrm{Ca}^{2+}$-ATPase (SERCA) transporter needs ATP to function [17]. High levels of intracellular $\mathrm{Ca}^{2+}$ induce the conversion, via limited proteolysis and sulfhydryl oxidation, of xanthine dehydrogenase to xanthine oxidase $(\mathrm{XO})$ in endothelial cells mainly, an isoform that produces superoxide anion and hydrogen peroxide $\left(\mathrm{H}_{2} \mathrm{O}_{2}\right)$ from oxygen [18]. The acidic conditions exert a strong inhibitory effect on the mitochondrial permeability transition pore (mPTP) [19], despite the presence of inducing factors opening such as $\mathrm{Ca}^{2+}$ and inorganic phosphate overload, oxidative stress and ADP. The MPTP is an inner mitochondrial membrane protein channel that, when it is open under certain conditions, mediates non-selective permeability to molecules less than $1.5 \mathrm{kDa}$, collapsing the mitochondrial membrane potential and uncoupling oxidative phosphorylation, leading to ATP depletion, mitochondrial matrix swelling and cell death through apoptosis and necrosis [20]. In addition, acidosis and low levels of ATP reduces the myocardial contractile activity [21].

The coronary revascularization postmyocardial ischemia rapidly increases the level of tissue oxygenation, which triggers a series of mechanisms producing LMRI. The most important mediators of this process are described below.

\subsection{Oxidative stress}

During the first minutes of the onset of myocardial reperfusion, a burst of ROS occurs, in accordance with several experiments demonstrating direct measurements of free radicals in isolated hearts and in vivo I/R models [8, 10-13]. The potential enzymatic sources of ROS production in cardiac tissue exposed to $\mathrm{I} / \mathrm{R}$ are xanthine oxidase $(\mathrm{XO})$ in endothelial cells, nicotinamide adenine dinucleotide phosphate (NADPH) oxidase (NOX) in neutrophils, mETC, uncoupled nitric oxide synthase (uncNOS), cytochrome P450, lipoxygenase/cyclooxygenase and monoamine oxidase [22]. XO activation and ATP catabolism to hypoxanthine occur in ischemic period, generating high levels of ROS together with uric acid from oxygen and accumulated hypoxanthine (or xanthine), when blood flow is restored [18]. The important role of NOX family in the MRI has been shown in experimental studies where NOX-isoformspecific knockout mice have significantly reduced infarct sizes compared to wild-type (WT) controls, confirming these results in buffer-perfused Langendorff models [23]. Cardiolipin peroxidation and cytochrome oxidase uncoupling in ischemic period results in the inhibition of electron flux through mETC, ATP depletion and increased superoxide anion generation, a situation that persists in the reperfusion where the Krebs cycle is reactivated and high levels of tissue oxygen can lead to increased ROS production [24]. Tetrahydrobiopterin $\left(\mathrm{BH}_{4}\right)$, a NOS cofactor, suffers oxidation to dihydrobiopterin in prolonged ischemia, resulting in loss of NOS enzyme affinity by the substrate L-citrulline together with a shift in the generation of nitric oxide (NO), a potent vasodilator, to superoxide anion during reperfusion [24, 25]. 

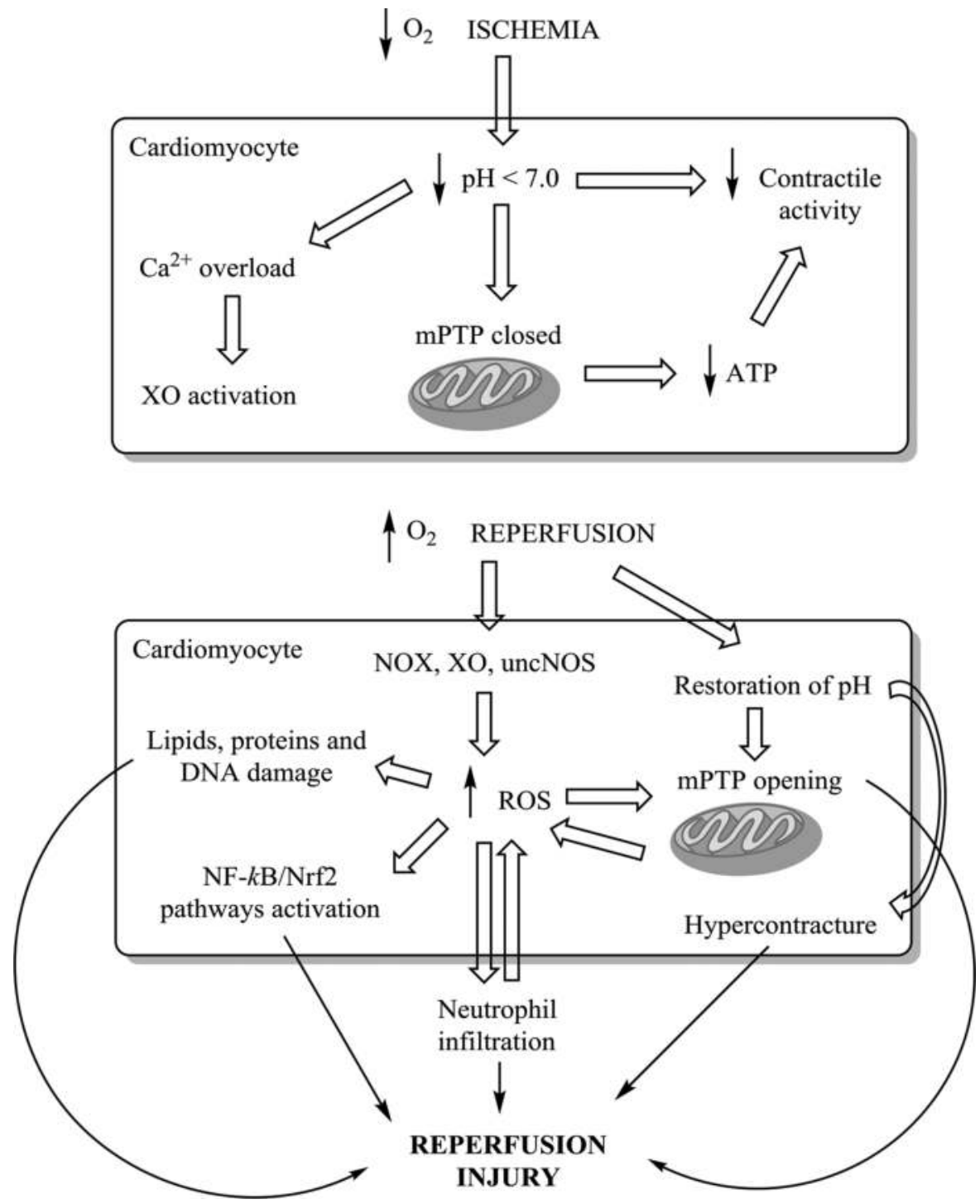

Figure 1. Schematic representation of the pathophysiological mechanism involved in myocardial damage due to I/R. ATP, adenosine triphosphate; mPTP, mitochondrial permeability transition pore; NOX, NADPH oxidase; NF- $\kappa \mathrm{B}$, nuclear factor kappa B; Nrf2, nuclear factor-erythroid 2-related factor 2; ROS, reactive oxygen species; uncNOS, uncoupled nitric oxide synthase; $\mathrm{XO}$, xanthine oxidase; $\mathrm{Ca}^{2+}$, calcium; DNA, deoxyribonucleic acid.

Exacerbation of oxidative stress during postischemia myocardial reperfusion overwhelms the endogenous antioxidant defenses, causing free radical propagation reactions with direct damage to cellular biomolecules as lipid peroxidation, protein oxidation/nitration and DNA 
damage $[24,26]$. The main effecter of ROS-induced damage is the highly reactive hydroxyl radical generated from Fenton/Haber-Weiss reactions and peroxynitrite (reviewed in Section 3) [24], demonstrating its formation in a postischemia reperfused heart [11]. In addition, ROS can induce activation both of nuclear factor kappa B (NF- $\kappa \mathrm{B})$ and nuclear factor-erythroid 2related factor 2 (Nrf2)-signaling pathways, although the ROS concentration threshold has not been experimentally determined [27]. NF- $\kappa B$ proteins are a family of transcription factors with a central role in regulating the expression of genes related with inflammation, immune response, cell proliferation and apoptosis [28-30], and different levels of ROS can both activate and inhibit NF- $k B$-signaling, depending on the context, with a high degree of complexity [31]. On the other hand, Nrf2 is a transcription factor that positively regulates the human antioxidant response element (ARE), leading to the gene expression of endogenous antioxidant defence system. Kelch-like ECH-associated protein 1 (Keap1) is a suppressor protein anchored in the cytoplasm that physically binds Nrf2, but oxidative stress facilitates the complex dissociation and Nrf2 nuclear translocation to ARE-containing promoters [32]. A study demonstrated that $\mathrm{Nrf} 2$ is indispensable for the regulation of both constitutive and inducible expression of antioxidants and phase-2 enzymes in mouse primary cardiomyocytes [33]. In clinical trials, the antioxidant therapy at the onset of reperfusion, in patients with AMI subjected to PCA, has mainly considered the use, alone or combined, of ROS scavengers, inhibitors of ROS sources, human recombinant antioxidant enzymes and reduced glutathione donor [14].

\subsection{Intracellular $\mathrm{pH}$}

The intracellular acidic $\mathrm{pH}$ generated in ischemia returns to physiological values during myocardial reperfusion [9]. Bond et al. [34] simulated I/R conditions in cultured neonatal rat cardiac myocytes, demonstrating that when intracellular acidic $\mathrm{pH}$ increases to 7.4 hypercontracture and cell death occur. In addition, free $\mathrm{Ca}^{2+}$ increases during simulated ischemia and in simulated reperfusion. Under conditions of ischemia, it was shown in cultured cardiac myocytes and perfused papillary muscles that inhibition of $\mathrm{Na}^{+} / \mathrm{H}^{+}$exchanger delayed the increase of intracellular $\mathrm{pH}$ after reperfusion and prevented reperfusion-induced cell killing, but not reduce the increase in intracellular-free $\mathrm{Ca}^{2+}$ [35]. By contrast, reperfusion with inhibition of $\mathrm{Na}^{+} / \mathrm{Ca}^{2+}$ exchanger decreases intracellular free $\mathrm{Ca}^{2+}$ but did not reduce cell killing. These results suggest that acidotic $\mathrm{pH}$ is generally protective in $\mathrm{I} / \mathrm{R}$, and $\mathrm{Na}^{+} / \mathrm{H}^{+}$exchanger contributes to reperfusion washout effect on intracellular acidic $\mathrm{pH}$, leading to a $\mathrm{Ca}^{2+}$-independent lethal reperfusion injury in cardiomyocytes.

\subsection{The mPTP opening}

Recently, it has been proposed that various potential protein components either to form the molecular structure of the MPTP or to regulate its opening [20,36]. It was shown that the mPTP opening occurs within the first few minutes postischemia myocardial reperfusion [37], with both burst of oxidative stress and intracellular $\mathrm{pH}$ normalization (possibly due to the inhibitory effect of acid $\mathrm{pH}$ on $\mathrm{mPTP}$ is removed) as the main contributing factors [38, 39]. On the other hand, $\mathrm{Ca}^{2+}$ overload seems not to be a causative factor in $\mathrm{I} / \mathrm{R}$ model. In adult rat myocytes, both 
cytosolic and mitochondrial $\mathrm{Ca}^{2+}$ increased during ischemia but decreases to basal levels in the first minutes of reperfusion. $\mathrm{Ca}^{2+}$ overload occurred late in both compartments, event that was prevented by mPTP inhibitors. Besides, intramitochondrial $\mathrm{Ca}^{2+}$ chelation did not prevent cell death after reperfusion. Thus, $\mathrm{Ca}^{2+}$ overload appears to be the consequence of bioenergetic failure after mPTP opening [38]. Another study showed that, at the onset of reperfusion, there is a transient increase in cytosolic $\mathrm{Ca}^{2+}$ levels together with a simultaneous transient sarcoplasmic reticulum $\mathrm{Ca}^{2+}$ depletion [40], corroborating the latter. The $\mathrm{mPTP}$ is a potential pharmacological target for prevent LMRI, and experimental studies with $\mathrm{MPTP}$ inhibitors (such as cyplosporin A), at the onset of myocardial reperfusion, has been reported to reduce MI size by $40-50 \%$ [41-44].

\subsection{Inflammation}

Ischemia is associated with slow infiltration of neutrophils, but recruitment toward the necrotic zone is favored after reperfusion by increased ROS exacerbation that triggers upregulation of adhesion molecules (P-selectin, CD11/CD18, ICAM-1) in cardiomyocytes, with cytokines (TNF $\alpha$, IL-1, IL-6, IL-8, NAP-1, PAF, MIP-2) and complement, which are released from ischemic-reperfused myocardium. Neutrophils adhesion to coronary vascular endothelium occurs rapidly (within minutes) after onset of reperfusion, with abundant accumulation into the infarct zone during the following 6 hours. Neutrophils release more than 20 different proteolytic enzymes (hydrolases, metalloproteinases, and proteases) and are a major ROS source by generating superoxide anions through NOX, positioning them as important contributors to MRI [45].

\section{Cardioprotection by combined antioxidant therapy}

After reviewing the most relevant pathophysiological processes of myocardial ischemiareperfusion injury, the central role being played by the burst of oxidative stress in the first minutes of revascularization certainly has positioned itself as a pharmacological target of choice. In the following section, we describe the molecular basis of an innovative combined antioxidant therapy, which includes a reinforcement of endogenous antioxidant defences, aimed to prevent or at least ameliorate the MRI in patients with AMI undergoing PCA.

\subsection{Ascorbate}

Vitamin C (ascorbic acid or ascorbate) is a potent water-soluble antioxidant in humans, which cannot be endogenously synthesized [46] and must be incorporated through vegetables and fruits [47]. Vitamin $C$ is an electron donor and is oxidized to dehydroascorbate when acting as a reducing agent, returning to reduced form when is used by the cell [48] (Figure 2). A study in a group of apparently healthy adult nonsmoking population showed an inverse correlation between plasma vitamin C and products of oxidative damage to DNA, proteins and lipids [49]. Another study evaluated oxidant and antioxidant parameters in the blood of the patients with MI before and after thrombolysis and showed that the activity of superoxide dismutase (SOD), 
an antioxidant enzyme, was significantly reduced, whereas the activity of $\mathrm{XO}$, an oxidant enzyme, together with the levels of malondialdehyde (MDA), a lipid peroxidation biomarker, significantly increased after reperfusion. These parameters improved to normal or nearnormal levels when patients were supplemented with oral vitamin C postreperfusion [50], confirming the in vivo antioxidant capacity of vitamin C. Other properties of this compound are described in the following experiments. Ascorbic acid, together vitamin E, reverse endothelial dysfunction through a modulator effect by upregulating endothelial NOS (eNOS) and downregulating NOX on the vascular wall [51]. In essential hypertensive patients, impaired endothelium-dependent vasodilation improved with vitamin $\mathrm{C}$ supplementation, an effect that can be reversed by a NOS inhibitor, suggesting a restoration of NO availability and oxidative stress-mediated endothelium impairment in this pathology [52]. Pretreatment with vitamin $C$ prevents vascular function damage and release of IL- 6 induced by endothelin-1 in humans [53]. Intracellular vitamin $C$ in human cell lines and primary endothelial cells, together with cell cultures in medium with dehydroascorbic acid, showed significantly decreased TNF $\alpha$-induced NF- $\kappa$ B activation [54].
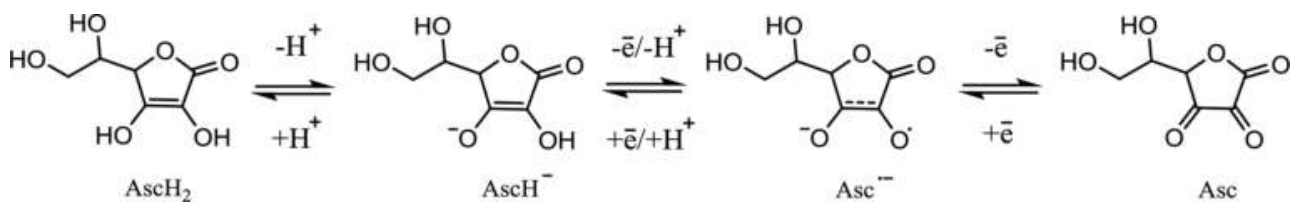

Figure 2. Oxidation of ascorbate $\left(\mathrm{AscH}^{-}\right)$to dehydroascorbic acid (Asc) for the loss of two electrons in succession, through the formation of ascorbyl radical intermediate $\left(\mathrm{Asc}^{{ }^{-}}\right)$. Importantly, ascorbate is the ionized form of ascorbic acid $\left(\mathrm{AscH}_{2}\right)$ at physiological $\mathrm{pH}(7.4)$.

Vitamin C has been used in I/R models. Gao et al. [55] demonstrated that in isolated rat hearts subjected to I/R, glutathione monoethyl ester (GSHme), but no ascorbic acid, administered at the onset of reperfusion exerted protective effects against MRI. Furthermore, GSHme coadministered together with ascorbic acid had enhanced protective effects, suggesting a synergistic effect between the two compounds. Another in vivo experimental study showed that intravenous (IV) administration of vitamin C or vitamin C plus vitamin E, prior to coronary occlusion following reperfusion, had not significant differences in infarct size compared to the control group. Besides, vitamin $\mathrm{C}$ alone tends to increase infarct size, whereas the vitamin combination tends to decrease [56]. The clinical trials in which vitamin $C$ is orally administered, in combination with other vitamins, in different doses to patients with cardiovascular history showed no beneficial cardioprotective long-term effects [27]. In patients with AMI subjected to PCA, administration of vitamin C orally $(2.0 \mathrm{~g})$ followed by a constant infusion $(20 \mathrm{mg} / \mathrm{min})$, before reperfusion, did not suppress the rapid and transient increase in levels of urinary 8-epiprostaglandin F2 $\alpha$ (8-epi-PGF2 $\alpha$ ), a biomarker of oxidative stress in vivo, after PCA [57]. A review [14] of the cardioprotective strategies using vitamin $C$ in combination with other vitamins in AMI followed by restoration of coronary blood flow showed variable results when administered orally, but when an infusion of vitamin C (1000 mg/12 h) was followed by oral doses $(1200 \mathrm{mg} / 24 \mathrm{~h}$ ) and vitamin E $(600 \mathrm{mg} / 24 \mathrm{~h})$, positive clinical outcomes were obtained 
within a composite endpoint. According to the latter, a study in patients undergoing elective percutaneous coronary intervention for stable angina showed that $1 \mathrm{~g}$ vitamin $\mathrm{C}$ administered by infusion ( $16.6 \mathrm{mg} / \mathrm{min}), 1$ hour before of intervention, improved the impaired microcirculatory reperfusion and had significantly reduced plasma levels of oxidative stress biomarkers [58].

These results could be explained by the fact that oral administration of vitamin $\mathrm{C}$ shows a plasma concentration-time profile, in a dose range of $200-2500 \mathrm{mg} / \mathrm{day}$, producing a steadystate plasma concentration approximately by $80 \mu \mathrm{mol} / \mathrm{l}(0.08 \mathrm{mmol} / \mathrm{l})$, due to apparent saturation of tissue uptake and in less degree by function of oral bioavailability and renal excretion [59]. At these physiological concentrations, superoxide anion reacts with $\mathrm{NO}$ at a rate $10^{4}$-fold greater than that at which it reacts with ascorbic acid (Table 1A and C), situation that is favored during the ROS burst in the first minutes of postischemia myocardial reperfusion because superoxide anion levels are exacerbated.

\begin{tabular}{lll}
\hline & Reaction & Rate constant $\left(\mathbf{M}^{-1} \mathbf{s}^{-1}\right)$ \\
\hline (A) & $\mathrm{O}_{2}{ }^{-}+\cdot \mathrm{NO} \rightarrow \mathrm{ONOO}^{-}$ & $7 \times 10^{9}$ \\
(B) $\quad \mathrm{O}_{2}{ }^{-}+\mathrm{SOD} \rightarrow \mathrm{O}_{2}+\mathrm{H}_{2} \mathrm{O}_{2}$ & $2 \times 10^{9}$ \\
(C) $\quad \mathrm{O}_{2}{ }^{-}+\mathrm{AscH}_{2} \rightarrow$ Products & $2.7-3.3 \times 10^{5}$ \\
\hline
\end{tabular}

ONOO-, peroxynitrite; $\mathrm{H}_{2} \mathrm{O}_{2}$, hydrogen peroxide; $\mathrm{O}_{2}$, molecular oxygen [60-62].

Table 1. Comparison of the reaction rate constants of superoxide anion $\left(\mathrm{O}_{2}{ }^{-{ }^{-}}\right)$with nitric oxide $\left({ }^{\circ} \mathrm{NO}\right)$, superoxide dismutase (SOD) and ascorbic acid $\left(\mathrm{AscH}_{2}\right)$.

Superoxide anion reacts avidly with $\mathrm{NO}$ to form peroxynitrite $\left(\mathrm{ONOO}^{-}\right)$(Table 1A), an agent very reactive and toxic to biomolecules, with a constant rate higher than that of the reaction between superoxide anion and SOD (Table 1B). Furthermore, peroxynitrite (pKa at $37^{\circ} \mathrm{C}=6.8$ ) can be protonated in medium with acidotic $\mathrm{pH}$ during ischemia, resulting in $\mathrm{ONOOH}$ that is inherently unstable. Reperfusion restored the intracellular $\mathrm{pH}$ to physiologic levels, favoring decomposition of $\mathrm{ONOOH}$ to hydroxyl radical and nitrogen dioxide radical (Figure 3) [24], both responsible for generating oxidative stress and nitrosative stress damage to cardiomyocytes. Thus, peroxynitrite contributes to MRI generating lipid peroxidation and protein nitration in tyrosine residues, affecting the function and structure of the latter; oxidation of thiol groups related to cell antioxidant capacity; rupture of double-stranded DNA; and $\mathrm{BH}_{4}$ NOS cofactor oxidation, which reduces the formation of NO [63].

Jackson et al. [64] demonstrated in vitro that supraphysiologic vitamin C concentration of 10 $\mathrm{mmol} / \mathrm{l}$ is needed to overcome the competition with $\mathrm{NO}$ for superoxide. Consequently, only IV infusion can achieve these plasma ascorbate levels. It has been documented that the use of high doses of IV vitamin C over $10 \mathrm{mmol} / \mathrm{l}$ in patients appears to have a positive safety profile, but it should be avoided in patients with renal function impairment or glucose-6-phosphate 
dehydrogenase deficiency [65]. Human plasma vitamin C concentration-time profile following short-term IV infusion shows peak concentrations higher than $20 \mathrm{mmol} / \mathrm{l}$, remaining over $10 \mathrm{mmol} / \mathrm{l}$ for 3 hours [66]. It is important to note that vitamin $\mathrm{C}$ needs to be incorporated into the cell to exert its effects. Specific $\mathrm{Na}^{+}$-dependent transporters for ascorbic acid (reduced form) are called SVCT1 and SVCT2, while transporters for dehydroascorbic acid (oxidized form) are members of GLUT family (GLUT1/3/4) that facilitate transport of glucose [67]. These transporters are expressed in the human myocardium [68-70].

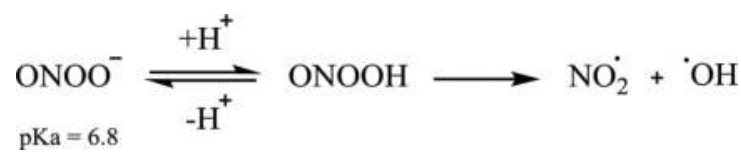

Figure 3. Formation of hydroxyl radical $\left({ }^{\circ} \mathrm{OH}\right)$ and nitrogen dioxide radical $\left(\mathrm{NO}_{2}{ }^{\circ}\right)$ from peroxynitrite $\left(\mathrm{ONOO}^{-}\right)$ through an intermediary peroxynitrous acid $(\mathrm{ONOOH})$.

\subsection{N-Acetyl cysteine}

When ascorbate is oxidized to dehydroascorbate, it can return to its reduced form through a reduced glutathione (GSH)-dependent recycling mechanism inside the cell, which may be direct [71] or enzyme mediated [72] (Figure 4) and can lead to a dehydroascorbate concentration-dependent decrease in intracellular GSH levels [71, 73, 74]. This process has been described in human erythrocytes [73], bovine aortic endothelial cells [74], among others and fulfills a function of blood antioxidant reserve [75]. Glutathione ( $\gamma$-glutamyl-cysteinyl-glycine) is an endogenous agent playing a primary role of nonenzymatic antioxidant defence together with participating in metabolic processes and cellular regulation. It has a reduced form (GSH) and an oxidized form (GSSG) which are interconvertible. It is synthesized in all cell types of the organism, being mostly in the cytosol and to a lesser extent in the extracellular plasma [76].

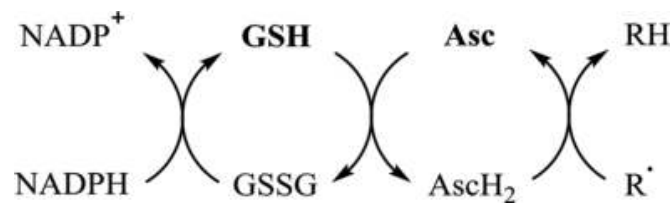

Figure 4. Reduced glutathione (GSH)-dependent reduction of dehydroascorbic acid (Asc), which may be mediated directly or by enzyme. $\mathrm{NADPH}$, nicotinamide adenine dinucleotide phosphate (reduced form); $\mathrm{NADP}^{+}$, nicotinamide adenine dinucleotide phosphate (oxidized form); GSSG, oxidized glutathione; $\mathrm{AscH}_{2}$, ascorbic acid; $\mathrm{RH}$, unsaturated fatty acid chain; $R^{\bullet}$, lipid alkyl radical.

If we consider an IV administration of high doses of vitamin C before, during and after PCA in patients with AMI, the burst of ROS will be counteracted by ascorbic acid, which generates large amounts of dehydroascorbic acid. We hypothesized that the latter interact with endogenous GSH and will cause a drop in their levels, limiting the cardioprotective effect. For this reason, we believe essential to reinforcement the endogenous antioxidant defence system with 
a GSH donor, such as $\mathrm{N}$-acetyl cysteine, to optimize antioxidant therapy. Furthermore, as above-mentioned, coadministration of a GSH donor and vitamin $\mathrm{C}$ tend to have a synergistic protective effect on infarct size in an I/R model of isolated rat heart [56].

$\mathrm{N}$-Acetyl cysteine (NAC) is a drug currently used in clinic that has demonstrated a good safety profile when administered orally, although adverse effects will be more noticeable at high doses (>3 g/day) or IV administration (e.g., for the treatment of paracetamol overdose) [77]. In experimental I/R models, high NAC dose administrated intracoronary with a radiographic contrast in pigs, at the onset of reperfusion, was safe, reduced platelet reactivity and there was a trend toward a better cardiac function at $24 \mathrm{~h}$, but there was no significant difference in the myocardial infarct size and did not provide significant renal protection compared to control group [78]. On the other hand, in a rat I/R model, NAC administration by continuous infusion before, during and after reperfusion produced a significant limitation of the infarct size compared to control group, but injection of NAC bolus with the same total dose, before and at onset of reperfusion, failed to reduce it [79]. In clinical trials, group of patients undergoing coronary artery bypass and/or valve surgery treated with IV infusion of NAC, before and after of surgery, decreases the incidence of postoperative atrial fibrillation compared to control group [80]. LIPSIA-N-ACC trial [81], a randomized, single-blind, controlled trial, was designed to measure the effects of high doses of NAC on contrast-induced nephropathy (CIN) and reperfusion injury in ST-segment elevation MI patients undergoing primary angioplasty intervention (PCI) with moderate contrast volumes. CIN is the acute deterioration of renal function occurring after intravascular administration of contrast media that is not attributable to other causes, defined as increase in serum creatinine $>0.3 \mathrm{mg} / \mathrm{dL}$ or $25 \%$ above baseline levels within 48 hours after contrast administration, which is associated with increased rates of morbidity and mortality. Of the 251 patients enrolled, 126 were randomized to the NAC treated group and 125 to the placebo group. NAC was administered as an IV bolus (1200 mg) before angioplasty and twice daily for 48 hours after angioplasty. In addition, all patients and controls were hydrated with IV infusion of $\mathrm{NaCl}(0.9 \%)$, at a rate of $1 \mathrm{ml} / \mathrm{kg}$ of body weight per hour for $12 \mathrm{~h}$, after PCI. Iopromide was used as a nonionic low-osmolality contrast agent for PCI. In the primary outcomes, CIN $(>25 \%$ increase in serum creatinine level $<72 \mathrm{~h}$ after randomization) occurred in $14 \%$ in the NAC-treated group and $20 \%$ in the placebo group, with no significant differences; the MRI (measured as myocardial salvage index by MRI) was also not statistically significant difference in both groups, so it is concluded that NAC not provide an additional clinical benefit to placebo with respect to CIN and MRI. However, activated oxygen protein products and oxidized low-density lipoprotein were evaluated as oxidative stress markers in blood plasma (in venous blood samples collected before, immediately after PCI, and subsequently for up to 3 days) and found that the NAC-treated group had a significant reduction $(20 \%)$ of these markers, while the placebo group had no significant differences. In another study, patients with AMI that received NAC infusion (a total dose of $15 \mathrm{~g} / 24 \mathrm{~h}$ ), combined with IV nitroglycerin and streptokinase, were well tolerated together with having significantly lesser oxidative stress, a trend toward more rapid reperfusion and better preservation of left ventricular function compared to control group [82]. 


\subsection{Deferoxamine}

It has been shown in $\mathrm{I} / \mathrm{R}$ models of isolated perfused heart that during a period of ischemia the amount of tissue available iron ( $\mathrm{Fe}$ ) increases in a time-dependent manner. Fe is rapidly mobilized through the perfusion fluid leading to very high Fe levels (up to 50-fold compared to pre-ischemic values) in the first small volumes of coronary flow fractions (CFF), returning to baseline over time. In addition, the levels of Fe in the CFFs correlated well with the loss of cardiac function following global ischemia of varying duration [83]. Similarly, the Fe levels increase up to 30-fold in cardiac tissue during ischemia, in a time-dependent manner, due to acidification in ischemia because this effect contributes tremendously to the mobilization of Fe from intracellular ferritin storage. After reperfusion, tissue Fe levels decrease, although it is known that the superoxide anion contributes to the mobilization of Fe from ferritin [84-86]. Langendorff models with myocardial iron overload develop different functional, biochemical and ultrastructural alterations as compared to control groups of myocardial $I / R$, which are prevented by deferoxamine (DFO), an iron chelator [87], realizing the harmful tissue effect of Fe high levels. The role of Fe in the postischemia MRI has been demonstrated in experimental models by the use of iron chelators at the onset of reperfusion, improving cardiac function relative to control group [88, 89]. Furthermore, a long-term study conducted in randomly selected men aged $42,48,54$ and 60 , who had no symptoms of coronary heart disease at entry, showed that elevated levels of serum ferritin (stored $\mathrm{Fe}$ ) was a strong risk factor for developing AMI [90].

Physiologically, transition metals, such as iron, are mainly stored or complexed. However, under certain pathological conditions, the nonchelated state iron levels are increased, thus generating oxidative stress. Reduced iron $\left(\mathrm{Fe}^{2+}\right)$ can react with hydrogen peroxide to generate hydroxyl radical $\left({ }^{\circ} \mathrm{OH}\right)$, a process known as Fenton reaction (Table 2A). At the same time, oxidized iron $\left(\mathrm{Fe}^{3+}\right)$ can react with superoxide anion to form again $\mathrm{Fe}^{2+}$ and oxygen (Table $2 \mathbf{B}$ ). The sum of the Fenton reaction and the superoxide-mediated reduction of $\mathrm{Fe}^{3+}$ originates the Haber-Weiss reaction (Table 2C), where hydroxyl radical is generated from superoxide anion and hydrogen peroxide [24]. Thus, during myocardial I/R increase, the $\mathrm{Fe}^{2+}$ availability and ROS levels that favor the formation of highly harmful and reactive hydroxyl radical through these redox reactions, can significantly contribute to MRI. This allows considering the iron overload during I/R as a pharmacological target for cardioprotection.

In addition, our interest is focused on the interaction between vitamin $C$ and iron. Ascorbate has pro-oxidant effect because of reduction of $\mathrm{Fe}^{3+}$ to $\mathrm{Fe}^{2+}$ (Table 2D), which is substrate to Fenton reaction leading to ROS production [92]. Under physiological conditions, in vivo studies with vitamin $C$ supplementation showed predominantly reduced levels in markers of oxidative damage in DNA, lipids and proteins, even in the presence of iron. These results were correlated with in vitro systems, such as isolated or cultured cells and biological fluids, where the antioxidant role, or no effect of vitamin C, predominated over a pro-oxidant role [91]. Considering that iron overload occurs in postischemia myocardial reperfusion, IV infusion of high doses of vitamin $\mathrm{C}$ at the onset of reperfusion could generate a strong interaction with iron, which not only decrease the concentration of ascorbate available in blood to counteract the burst of oxidative stress, reducing its antioxidant effect, but also favor pro-oxidant effects 
and ROS production. Thus, use of an iron chelator, as DFO, as adjuvant to antioxidant therapy with vitamin $C$ should be considered to reduce deleterious effects and maximize cardioprotection in patients with AMI being subjected to PCA. A experimental study in pigs showed that the combined use of vitamin C (100 mg/kg) and DFO $(60 \mathrm{mg} / \mathrm{kg})$, administered as IV infusion at the beginning, during and after reperfusion postischemia, had no difference in the measured cardiac parameters compared to the control group, although it was observed a trend toward reducing infarct size [94]. However, no markers of oxidative stress, apoptosis or other biochemical parameter related to myocardial damage were measured. Another study in sheep demonstrated that administration by IV infusion of vitamin C (1.5 g) and DFO (1 g) (in combination but not separately), before reperfusion, significantly protected against the development of ventricular arrhythmias induced by I/R, compared to control group [95].

\begin{tabular}{|c|c|c|}
\hline & Reaction & Rate constant $\left(\mathrm{M}^{-1} \mathrm{~s}^{-1}\right)$ \\
\hline (A) & $\mathrm{Fe}^{2+}+\mathrm{H}_{2} \mathrm{O}_{2} \rightarrow \mathrm{Fe}^{3+}+\cdot \mathrm{OH}+\mathrm{OH}^{-}$ & 76 \\
\hline (B) & $\mathrm{O}_{2}^{-}+\mathrm{Fe}^{3+} \rightarrow \mathrm{O}_{2}+\mathrm{Fe}^{2+}$ & $1.9 \times 10^{6}-10^{4}$ \\
\hline (C) & $\mathrm{O}_{2}^{\cdot}{ }^{-}+\mathrm{H}_{2} \mathrm{O}_{2} \rightarrow \mathrm{O}_{2}+\cdot \mathrm{OH}+\mathrm{OH}^{-}$ & $<2.3$ \\
\hline (D) & $\mathrm{AscH}^{-}+\mathrm{Fe}^{3+} \rightarrow \mathrm{Asc}^{\cdot-}+\mathrm{Fe}^{2+}+\mathrm{H}^{+}$ & $10^{2}$ \\
\hline
\end{tabular}

Table 2. Fenton (A), Haber-Weiss (C) and others redox reactions.

DFO has shown beneficial effects in experimental models of I/R. Isolated, perfused rabbit hearts treated with DFO, during ischemia and reflow, demonstrated improved functional and metabolic recovery of myocardium together a reduction in reperfusion-induced oxygen freeradical generation, compared to control group [96]. In a canine model of I/R, DFO pretreatment before ischemia, but not at the beginning of reperfusion, reduced significantly infarct size and release of GSSG into the coronary sinus during early reflow, compared to control group [97]. Decrease in infarct size by early treatment with DFO was corroborated by another independent study in canine model of I/R [98]. Regarding clinical trials, patients undergoing coronary artery bypass grafting, that received an IV infusion of DFO for 8 hours, prevented the increase in oxidative stress markers and improving ventricular functional parameters after surgery, compared to control group [99]. Other clinical trial in patients with ST-elevation MI subjected to primary percutaneous coronary intervention (PPCI) showed that administration of IV bolus of DFO (500 mg) immediately before surgery, followed by a $12-\mathrm{h}$ infusion $(50 \mathrm{mg} / \mathrm{kg})$, significantly reduced in plasma F2-isoprostane levels, with no difference in infarct size, after PPCI compared to placebo group [100]. 


\section{Conclusion and perspectives}

In this chapter, we have reviewed the molecular processes involved in the pathophysiology of myocardial damage by postischemia reperfusion, emphasizing the central role of oxidative stress as the key mediator of this damage. Accordingly, increased ROS production can give rise to the occurrence of events ranging from inflammation, damage to biomolecules and metabolic cell impairment to even cell death. From this paradigm, a novel antioxidant therapy is proposed as cardioprotective action in patients with AMI subject to PCA. This treatment considers the use of vitamin C (sodium ascorbate) in high doses administered intravenously, combined with NAC and DFO prior to surgery so as to optimize and enhance the beneficial effects and reduce the harmful effects on myocardium occurring in this setting (Figure 5). However, the results from different experimental models are controversial and more studies are still lacking. On this line, it is important to note that MRI is an unsolved problem in the clinical practice. Different strategies to prevent this damage during surgery for revascularization in patients with AMI have been tried without conclusive results, and we expect that our proposal can contribute as an effective, low risk and economic alternative in the near future.

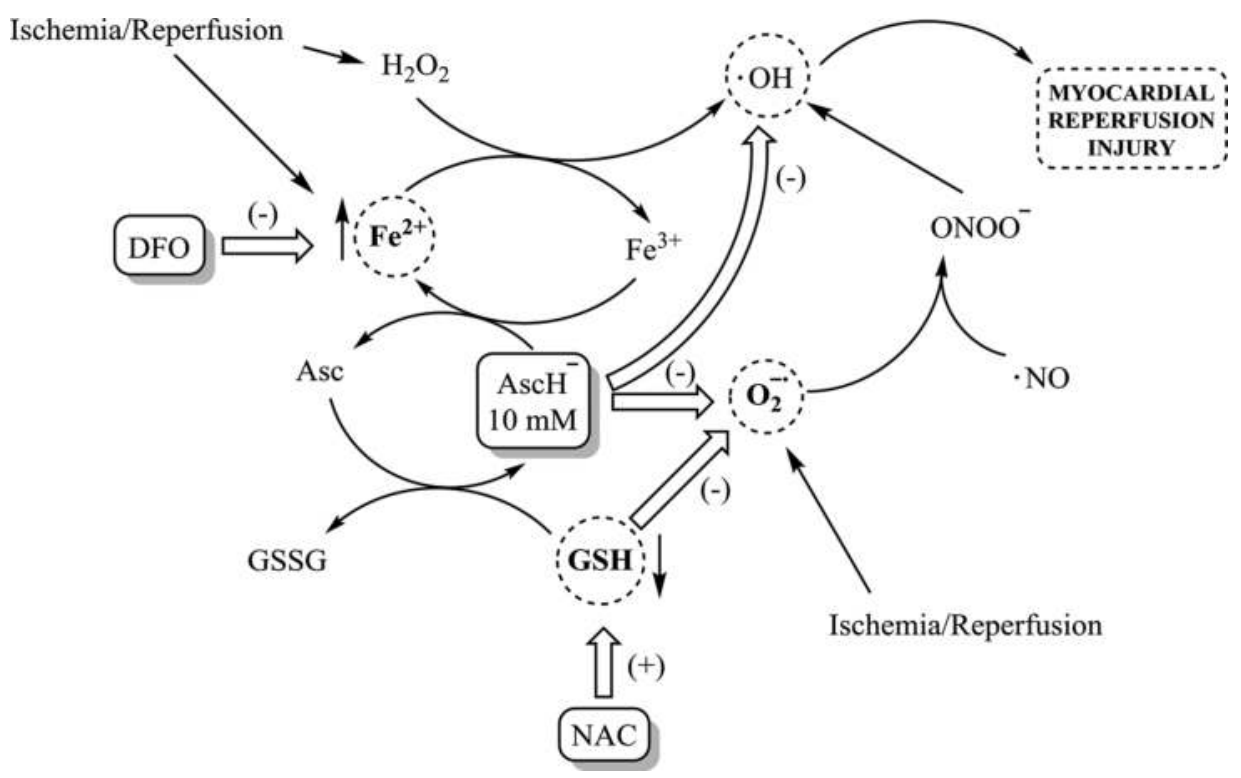

Figure 5. Diagram of the proposed combined antioxidant therapy for patients with AMI subject to PCA, which considers the use of: (i) ascorbate $\left(\mathrm{AscH}^{-}\right)$in high doses to compete with nitric oxide ( $\left.{ }^{\circ} \mathrm{NO}\right)$ by superoxide anion $\left(\mathrm{O}_{2}{ }^{-}\right)$; (ii) deferoxamine (DFO) to counteract reduced iron $\left(\mathrm{Fe}^{2+}\right)$ overload and thus prevent the Fenton reaction and interaction with $\mathrm{AscH}^{-}$; (iii) $\mathrm{N}$-acetyl cysteine (NAC) as reduced glutathione (GSH) donor to reinforce the antioxidant defense system and mitigate its interaction with dehydroascorbic acid (Asc). In this way, it counteracts directly and indirectly the hydroxyl radical $\left({ }^{\circ} \mathrm{OH}\right)$, which is the main mediator of myocardial damage by oxidative stress during reperfusion. $\mathrm{H}_{2} \mathrm{O}_{2}$, hydrogen peroxide; GSSG, oxidized glutathione; $\mathrm{ONOO}^{-}$, Peroxynitrite; $\mathrm{Fe}^{3+}$, oxidized iron. 


\section{Acknowledgements}

This study was supported by the Fondo de Fomento al Desarrollo Científico y Tecnológico (FONDEF), grant ID15I10285.

\section{Nomenclature}

Asc

$\mathrm{AscH}_{2}$

AMI

ARE

ATP

CFF

DFO

eNOS

8-epi-PGF2 $\alpha$

GSH

GSSG

IHD

IL-6

I/R

IV

kDA

LMRI

PCA

MDA

mETC

MI

MRI

mPTP

NAC

NF- $\kappa B$

NO

NOX

Nrf2 dehydroascorbic acid

ascorbic acid

acute myocardial infarction

antioxidant response elements

adenosine triphosphate

coronary flow fraction

deferoxamine

endothelial nitric oxide synthase

8-epi-prostaglandin F2 $\alpha$

reduced glutathione

oxidized glutathione

ischemic heart disease

interleukin 6

ischemia-reperfusion

intravenous

kilo dalton

lethal myocardial reperfusion injury

percutaneous coronary angioplasty

malondialdehyde

mitochondrial electron transport chain

myocardial infarction

myocardial reperfusion injury

mitochondrial permeability transition pore

$\mathrm{N}$-acetyl cysteine

nuclear factor kappa B

nitric oxide

NADPH oxidase

nuclear factor-erythroid 2-related factor 2 


$\begin{array}{ll}\text { OH } & \text { hydroxyl radical } \\ \text { ONOO}^{-} & \text {peroxynitrite } \\ \text { PPCI } & \text { primary percutaneous coronary intervention } \\ \text { ROS } & \text { reactive oxygen species } \\ \text { SOD } & \text { superoxide dismutase } \\ \text { TNF } \alpha & \text { tumor necrosis factor alpha } \\ \text { XO } & \text { xanthine oxidase }\end{array}$

\section{Author details}

Pablo Parra and Ramón Rodrigo*

*Address all correspondence to: rrodrigo@med.uchile.cl

Molecular and Clinical Pharmacology Program, Institute of Biomedical Sciences, Faculty of Medicine, University of Chile, Santiago, Chile

\section{References}

[1] World Health Organization. The Top 10 causes of death [Internet]. [Updated: 2014-05]. Available from: http://www.who.int/mediacentre/factsheets/fs310/en/ [Accessed: 2015-12-06].

[2] World Health Organization. Global status report on noncommunicable diseases 2014. Geneva, Switzerland, World Health Organization, 2014. 298 p.

[3] Garcia-Dorado D, Rodríguez-Sinovas A, Ruiz-Meana M, Inserte J. Protection against myocardial ischemia-reperfusion injury in clinical practice. Revista Española de Cardiología (English Edition). 2014;67(5):394-404. DOI: 10.1016/j.rec.2014.01.010.

[4] White HD, Chew DP. Acute myocardial infarction. Lancet. 2008;372(9638):570-584. DOI: 10.1016/S0140-6736(08)61237-4.

[5] Yellon DM, Hausenloy DJ. Myocardial reperfusion injury. New England Journal of Medicine. 2007;357(11):1121-1135. DOI: 10.1056/NEJMra071667.

[6] Hausenloy DJ, Yellon DM. Myocardial ischemia-reperfusion injury: a neglected therapeutic target. Journal of Clinical Investigation. 2013;123(1):92-100. DOI: 10.1172/ JCI62874. 
[7] Jolly SR, Kane WJ, Bailie MB, Abrams GD, Lucchesi BR. Canine myocardial reperfusion injury. Its reduction by the combined administration of superoxide dismutase and catalase. Cardiovascular Research. 1984;54(3):277-285. DOI: 10.1161/01.RES.54.3.277

[8] Zweier JL, Flaherty JT, Weisfeldt ML. Direct measurement of free radical generation following reperfusion of ischemic myocardium. Proceedings of the National Academy of Sciences of the United States of America. 1987;84(5):1404-1407.

[9] Ambrosio G, Weisfeldt ML, Jacobus WE, Flaherty JT. Evidence for a reversible oxygen radical-mediated component of reperfusion injury: reduction by recombinant human superoxide dismutase administered at the time of reflow. Circulation. 1987;75(1):282 291. DOI: 10.1161/01.CIR.75.1.282.

[10] Zweier JL, Rayburn BK, Flaherty JT, Weisfeldt ML. Recombinant superoxide dismutase reduces oxygen free radical concentrations in reperfused myocardium. Journal of Clinical Investigation. 1987;80(6):1728-1734. DOI: 10.1172/JCI113264.

[11] Zweier JL. Measurement of superoxide-derived free radicals in the reperfused heart. Evidence for a free radical mechanism of reperfusion injury. Journal of Biological Chemistry. 1988;263(3):1353-1357.

[12] Grill HP, Zweier JL, Kuppusamy P, Weisfeldt ML, Flaherty JT. Direct measurement of myocardial free radical generation in an in vivo model: effects of postischemic reperfusion and treatment with human recombinant superoxide dismutase. Journal of the American College of Cardiology. 1992;20(7):1604-1611. DOI: 10.1016/0735-1097(92)90457-X.

[13] Lecour S, Baouali AB, Maupoil V, Chahine R, Abadie C, Javouhey-Donzel A, et al. Demonstration of the production of oxygen-centered free radicals during electrolysis using E.S.R. spin-trapping techniques: effects on cardiac function in the isolated rat heart. Free Radical Biology and Medicine. 1998;24(4):573-579. DOI: 10.1016/ S0891-5849(97)00294-3.

[14] Rodrigo R, Libuy M, Feliú F, Hasson D. Molecular basis of cardioprotective effect of antioxidant vitamins in myocardial infarction. BioMed Research International. 2013;2013:437613. DOI: 10.1155/2013/437613.

[15] Neely JR, Grotyohann LW. Role of glycolytic products in damage to ischemic myocardium. Dissociation of adenosine triphosphate levels and recovery of function of reperfused ischemic hearts. Circulation Research. 1984;55(6):816-824. DOI: 10.1161/01.RES.55.6.816.

[16] Avkiran M, Marber M. $\mathrm{Na}^{+} / \mathrm{H}^{+}$exchange inhibitors for cardioprotective therapy: progress, problems and prospects. Journal of the American College of Cardiology. 2002;39(5):747-753. DOI: 10.1016/S0735-1097(02)01693-5.

[17] Rossi AE, Dirksen RT. Sarcoplasmic reticulum: the dynamic calcium governor of muscle. Muscle \& Nerve. 2006;33(6):715-731. DOI: 10.1002/mus.20512. 
[18] Sasaki M, Joh T. Oxidative stress and ischemia-reperfusion injury in gastrointestinal tract and antioxidant, protective agents. Journal of Clinical Biochemistry and Nutrition. 2007;40(1):1-12. DOI: 10.3164/jcbn.40.1.

[19] Bernardi P, Vassanelli S, Veronese P, Colonna R, Szabó I, Zoratti M. Modulation of the mitochondrial permeability transition pore. Effect of protons and divalent cations. Journal of Biological Chemistry. 1992;267(5):2934-2939.

[20] Ong SB, Samangouei P, Kalkhoran SB, Hausenloy DJ. The mitochondrial permeability transition pore and its role in myocardial ischemia reperfusion injury. Journal of Molecular and Cellular Cardiology. 2015;78:23-34. DOI: 10.1016/j.yjmcc.2014.11.005.

[21] Orchard $\mathrm{CH}$, Kentish JC. Effects of changes of $\mathrm{pH}$ on the contractile function of cardiac muscle. American Journal of Physiology. 1990;258(6 Pt 1):C967-C981.

[22] Granger DN, Kvietys PR. Reperfusion injury and reactive oxygen species: the evolution of a concept. Redox Biology. 2015;6:524-551. DOI: 10.1016/j.redox.2015.08.020.

[23] Braunersreuther V, Montecucco F, Asrih M, Pelli G, Galan K, Frias M, et al. Role of NADPH oxidase isoforms NOX1, NOX2 and NOX4 in myocardial ischemia/reperfusion injury. Journal of Molecular and Cellular Cardiology. 2013;64:99-107. DOI: 10.1016/ j.yjmcc.2013.09.007.

[24] Raedschelders K, Ansley DM, Chen DD. The cellular and molecular origin of reactive oxygen species generation during myocardial ischemia and reperfusion. Pharmacology \& Therapeutics. 2012;133(2):230-255. DOI: 10.1016/j.pharmthera.2011.11.004.

[25] Vásquez-Vivar J, Martásek P, Whitsett J, Joseph J, Kalyanaraman B. The ratio between tetrahydrobiopterin and oxidized tetrahydrobiopterin analogues controls superoxide release from endothelial nitric oxide synthase: an EPR spin trapping study. Biochemical Journal. 2002;362(Pt 3):733-739. DOI: 10.1042/bj3620733.

[26] Avery SV. Molecular targets of oxidative stress. Biochemical Journal. 2011;434(2):201210. DOI: 10.1042/BJ20101695.

[27] Rodrigo R, Prieto JC, Castillo R. Cardioprotection against ischaemia/reperfusion by vitamins $C$ and $E$ plus $n-3$ fatty acids: molecular mechanisms and potential clinical applications. Clinical Science. 2013;124(1):1-15. DOI: 10.1042/CS20110663.

[28] Gloire G, Legrand-Poels S, Piette J. NF-kappaB activation by reactive oxygen species: fifteen years later. Biochemical Pharmacology. 2006;72(11):1493-1505. DOI: 10.1016/ j.bcp.2006.04.011.

[29] Perkins N1, Gilmore TD. Good cop, bad cop: the different faces of NF-kappaB. Cell Death and Differentiation. 2006;13(5):759-772. DOI: 10.1038/sj.cdd.4401838.

[30] Kucharczak J, Simmons MJ, Fan Y, Gélinas C. To be, or not to be: NF-kappaB is the answer - role of Rel/NF-kappaB in the regulation of apoptosis. Oncogene. 2003;22(56): 8961-8982. DOI: 10.1038/sj.onc.1207230. 
[31] Morgan MJ, Liu ZG. Crosstalk of reactive oxygen species and NF- $\kappa B$ signaling. Cell Research. 2011;21(1):103-115. DOI: 10.1038/cr.2010.178.

[32] Hybertson BM, Gao B, Bose SK, McCord JM. Oxidative stress in health and disease: the therapeutic potential of Nrf2 activation. Molecular Aspects of Medicine. 2011;32(4-6): 234-246. DOI: 10.1016/j.mam.2011.10.006.

[33] Zhu H, Jia Z, Misra BR, Zhang L, Cao Z, Yamamoto M, et al. Nuclear factor E2-related factor 2-dependent myocardiac cytoprotection against oxidative and electrophilic stress. Cardiovascular Toxicology. 2008;8(2):71-85. DOI: 10.1007/ s12012-008-9016-0.

[34] Bond JM1, Chacon E, Herman B, Lemasters JJ. Intracellular $\mathrm{pH}$ and $\mathrm{Ca}^{2+}$ homeostasis in the $\mathrm{pH}$ paradox of reperfusion injury to neonatal rat cardiac myocytes. American Journal of Physiology. 1993;265(1 Pt 1):C129-C137. DOI: 10.1111/j. 1749-6632.1994.tb36714.x.

[35] Lemasters JJ, Bond JM, Chacon E, Harper IS, Kaplan SH, Ohata H, et al. The pH paradox in ischemia-reperfusion injury to cardiac myocytes. Experientia Supplementum. 1996;76:99-114. DOI: 10.1007/978-3-0348-8988-9_7.

[36] Morciano G, Giorgi C, Bonora M, Punzetti S, Pavasini R, Wieckowski MR, et al. Molecular identity of the mitochondrial permeability transition pore and its role in ischemia-reperfusion injury. Journal of Molecular and Cellular Cardiology. 2015;78:142-153. DOI: 10.1016/j.yjmcc.2014.08.015.

[37] Griffiths EJ, Halestrap AP. Mitochondrial non-specific pores remain closed during cardiac ischaemia, but open upon reperfusion. Biochemical Journal. 1995;307(Pt 1):9398. DOI: 10.1042/bj3070093.

[38] Kim JS, Jin $\mathrm{Y}$, Lemasters JJ. Reactive oxygen species, but not $\mathrm{Ca}^{2+}$ overloading, trigger $\mathrm{pH}$ - and mitochondrial permeability transition-dependent death of adult rat myocytes after ischemia-reperfusion. American Journal of Physiology - Heart and Circulatory Physiology. 2006;290(5):H2024-H2034. DOI: 10.1152/ajpheart.00683.2005.

[39] Seidlmayer LK, Juettner VV, Kettlewell S, Pavlov EV, Blatter LA, Dedkova EN. Distinct mPTP activation mechanisms in ischaemia-reperfusion: contributions of $\mathrm{Ca}^{2+}, \mathrm{ROS}$, $\mathrm{pH}$, and inorganic polyphosphate. Cardiovascular Research. 2015;106(2):237-248. DOI: 10.1093/cvr/cvv097.

[40] Valverde CA, Kornyeyev D, Ferreiro M, Petrosky AD, Mattiazzi A, Escobar AL. Transient $\mathrm{Ca}^{2+}$ depletion of the sarcoplasmic reticulum at the onset of reperfusion. Cardiovascular Research. 2010;85(4):671-680. DOI: 10.1093/cvr/cvp371.

[41] Hausenloy DJ, Maddock HL, Baxter GF, Yellon DM. Inhibiting mitochondrial permeability transition pore opening: a new paradigm for myocardial preconditioning?. Cardiovascular Research. 2002;55(3):534-543. DOI: 10.1016/ S0008-6363(02)00455-8. 
[42] Hausenloy DJ, Duchen MR, Yellon DM. Inhibiting mitochondrial permeability transition pore opening at reperfusion protects against ischaemia-reperfusion injury. Cardiovascular Research. 2003;60(3):617-625. DOI: 10.1016/j.cardiores.2003.09.025.

[43] Argaud L, Gateau-Roesch O, Muntean D, Chalabreysse L, Loufouat J, Robert D, et al. Specific inhibition of the mitochondrial permeability transition prevents lethal reperfusion injury. Journal of Molecular and Cellular Cardiology. 2005;38(2):367-374. DOI: 10.1016/j.yjmcc.2004.12.001.

[44] Skyschally A, Schulz R, Heusch G. Cyclosporine A at reperfusion reduces infarct size in pigs. Cardiovascular Drugs and Therapy. 2010;24(1):85-87. DOI: 10.1007/ s10557-010-6219-y.

[45] Vinten-Johansen J. Involvement of neutrophils in the pathogenesis of lethal myocardial reperfusion injury. Cardiovascular Research. 2004;61(3):481-497. DOI: 10.1016/j.cardiores.2003.10.011.

[46] Nishikimi M, Yagi K. Biochemistry and molecular biology of ascorbic acid biosynthesis. In: J. Robin Harris, editor. Subcellular Biochemistry. 25th ed. New York: Springer US; 1996. p. 17-39. DOI: 10.1007/978-1-4613-0325-1_2.

[47] Haytowitz DB. Information from USDA's Nutrient Data Bank. The Journal of Nutrition. 1995;125(7):1952-1955.

[48] Padayatty SJ, Katz A, Wang Y, Eck P, Kwon O, Lee JH, et al. Vitamin C as an antioxidant: evaluation of its role in disease prevention. Journal of the American College of Nutrition. 2003;22(1):18-35. DOI: 10.1080/07315724.2003.10719272.

[49] Krajcovicová-Kudlácková M, Dusinská M, Valachovicová M, Blazícek P, Pauková V. Products of DNA, protein and lipid oxidative damage in relation to vitamin C plasma concentration. Physiological Research. 2006;55(2):227-231.

[50] Bhakuni P, Chandra M, Misra MK. Effect of ascorbic acid supplementation on certain oxidative stress parameters in the post reperfusion patients of myocardial infarction. Molecular and Cellular Biochemistry. 2006;290(1-2):153-158. DOI: 10.1007/ s11010-006-9182-y.

[51] Ulker S, McKeown PP, Bayraktutan U. Vitamins reverse endothelial dysfunction through regulation of eNOS and $\mathrm{NAD}(\mathrm{P}) \mathrm{H}$ oxidase activities. Hypertension. 2003;41(3):534-539. DOI: 10.1161/01.HYP.0000057421.28533.37.

[52] Taddei S, Virdis A, Ghiadoni L, Magagna A, Salvetti A. Vitamin C improves endothelium-dependent vasodilation by restoring nitric oxide activity in essential hypertension. Circulation. 1998;97(22):2222-2229. DOI: 10.1161/01.CIR.97.22.2222.

[53] Böhm F, Settergren M, Pernow J. Vitamin C blocks vascular dysfunction and release of interleukin-6 induced by endothelin-1 in humans in vivo. Atherosclerosis. 2007;190(2): 408-415. DOI: 10.1016/j.atherosclerosis.2006.02.018. 
[54] Cárcamo JM, Pedraza A, Bórquez-Ojeda O, Golde DW. Vitamin C suppresses TNF alpha-induced NF kappa B activation by inhibiting I kappa B alpha phosphorylation. Biochemistry. 2002;41(43):12995-13002. DOI: 10.1021/bi0263210.

[55] Gao F, Yao CL, Gao E, Mo QZ, Yan WL, McLaughlin R, et al. Enhancement of glutathione cardioprotection by ascorbic acid in myocardial reperfusion injury. Journal of Pharmacology and Experimental Therapeutics. 2002;301(2):543-550. DOI: 10.1124/jpet. 301.2.543.

[56] Bellows SD, Hale SL, Simkhovich BZ, Kay GL, Kloner RA. Do antioxidant vitamins reduce infarct size following acute myocardial ischemia/reperfusion? Cardiovascular Drugs and Therapy. 1995;9(1):117-123. DOI: 10.1007/BF00877751.

[57] Guan W, Osanai T, Kamada T, Ishizaka H, Hanada H, Okumura K. Time course of free radical production after primary coronary angioplasty for acute myocardial infarction and the effect of vitamin C. Japanese Circulation Journal. 1999;63(12):924-928. DOI: 10.1253/jcj.63.924.

[58] Basili S, Tanzilli G, Mangieri E, Raparelli V, Di Santo S, Pignatelli P, et al. Intravenous ascorbic acid infusion improves myocardial perfusion grade during elective percutaneous coronary intervention: relationship with oxidative stress markers. JACC: Cardiovascular Interventions. 2010;3(2):221-229. DOI: 10.1016/j.jcin.2009.10.025.

[59] Graumlich JF, Ludden TM, Conry-Cantilena C, Cantilena LR Jr, Wang Y, Levine M. Pharmacokinetic model of ascorbic acid in healthy male volunteers during depletion and repletion. Pharmaceutical Research. 1997;14(9):1133-1139. DOI: 10.1023/A: 1012186203165.

[60] Pryor WA, Squadrito GL. The chemistry of peroxynitrite: a product from the reaction of nitric oxide with superoxide. American Journal of Physiology. 1995;268(5 Pt 1):L699_ L722.

[61] Gotoh N, Niki E. Rates of interactions of superoxide with vitamin E, vitamin C and related compounds as measured by chemiluminescence. Biochimica et Biophysica Acta (BBA) - General Subjects. 1992;1115(3):201-207. DOI: 10.1016/0304-4165(92)90054-X.

[62] Nishikimi M. Oxidation of ascorbic acid with superoxide anion generated by the xanthine-xanthine oxidase system. Biochemical and Biophysical Research Communications. 1975;63(2):463-468. DOI: 10.1016/0006-291X(75)90710-X.

[63] Kavdia M. Mathematical and computational models of oxidative and nitrosative stress. Critical Reviews in Biomedical Engineering. 2011;39(5):461-472. DOI: 10.1615/CritRevBiomedEng.v39.i5.60

[64] Jackson TS, Xu A, Vita JA, Keaney JF Jr. Ascorbate prevents the interaction of superoxide and nitric oxide only at very high physiological concentrations. Circulation Research. 1998;83(9):916-922. DOI: 10.1161/01.RES.83.9.916. 
[65] Padayatty SJ, Sun AY, Chen Q, Espey MG, Drisko J, Levine M. Vitamin C: intravenous use by complementary and alternative medicine practitioners and adverse effects. PLoS One. 2010;5(7):e11414. DOI: 10.1371/journal.pone.0011414.

[66] Duconge J, Miranda-Massari JR, Gonzalez MJ, Jackson JA, Warnock W, Riordan NH. Pharmacokinetics of vitamin C: insights into the oral and intravenous administration of ascorbate. Puerto Rico Health Sciences Journal. 2008;27(1):7-19.

[67] Rivas CI, Zúñiga FA, Salas-Burgos A, Mardones L, Ormazabal V, Vera JC. Vitamin C transporters. Journal of Physiology and Biochemistry. 2008;64(4):357-375. DOI: 10.1007/ BF03174092.

[68] Grover-McKay M, Walsh SA, Thompson SA. Glucose transporter 3 (GLUT3) protein is present in human myocardium. Biochimica et Biophysica Acta (BBA) - Biomembranes. 1999;1416(1-2):145-154. DOI: 10.1016/S0005-2736(98)00216-8.

[69] Savini I, Rossi A, Pierro C, Avigliano L, Catani MV. SVCT1 and SVCT2: key proteins for vitamin C uptake. Amino Acids. 2008;34(3):347-355. DOI: 10.1007/ s00726-007-0555-7.

[70] Rajan DP, Huang W, Dutta B, Devoe LD, Leibach FH, Ganapathy V, et al. Human placental sodium-dependent vitamin C transporter (SVCT2): molecular cloning and transport function. Biochemical and Biophysical Research Communications. 1999;262(3):762-768. DOI: 10.1006/bbrc.1999.1272.

[71] May JM, Qu ZC, Whitesell RR, Cobb CE. Ascorbate recycling in human erythrocytes: role of GSH in reducing dehydroascorbate. Free Radical Biology and Medicine. 1996;20(4):543-551. DOI: 10.1016/0891-5849(95)02130-2.

[72] Mendiratta S, Qu ZC, May JM. Enzyme-dependent ascorbate recycling in human erythrocytes: role of thioredoxin reductase. Free Radical Biology and Medicine. 1998;25(2):221-228. DOI: 10.1016/S0891-5849(98)00060-4.

[73] May JM, Qu Z, Morrow JD. Mechanisms of ascorbic acid recycling in human erythrocytes. Biochimica et Biophysica Acta (BBA) - General Subjects. 2001;1528(2-3):159-166. DOI: 10.1016/S0304-4165(01)00188-X.

[74] May JM, Qu Z, Li X. Requirement for GSH in recycling of ascorbic acid in endothelial cells. Biochemical Pharmacology. 2001;62(7):873-881. DOI: 10.1016/ S0006-2952(01)00736-5.

[75] Mendiratta S, Qu ZC, May JM. Erythrocyte ascorbate recycling: antioxidant effects in blood. Free Radical Biology and Medicine. 1998;24(5):789-797. DOI: 10.1016/ S0891-5849(97)00351-1.

[76] Wu G, Fang YZ, Yang S, Lupton JR, Turner ND. Glutathione metabolism and its implications for health. Journal of Nutrition. 2004;134(3):489-492. 
[77] Dodd S, Dean O, Copolov DL, Malhi GS, Berk M. N-acetylcysteine for antioxidant therapy: pharmacology and clinical utility. Expert Opinion on Biological Therapy. 2008;8(12):1955-1962. DOI: 10.1517/14728220802517901.

[78] Meyer M, Bell SP, Chen Z, Nyotowidjojo I, Lachapelle RR, Christian TF, et al. High dose intracoronary $\mathrm{N}$-acetylcysteine in a porcine model of ST-elevation myocardial infarction. Journal of Thrombosis and Thrombolysis. 2013;36(4):433-441. DOI: 10.1007/ s11239-013-0901-4.

[79] Abe M, Takiguchi Y, Ichimaru S, Tsuchiya K, Wada K. Comparison of the protective effect of $\mathrm{N}$-acetylcysteine by different treatments on rat myocardial ischemia-reperfusion injury. Journal of Pharmacological Sciences. 2008;106(4):571-577. DOI: 10.1254/ jphs.FP0071664.

[80] Ozaydin M, Peker O, Erdogan D, Kapan S, Turker Y, Varol E, et al. N-acetylcysteine for the prevention of postoperative atrial fibrillation: a prospective, randomized, placebocontrolled pilot study. European Heart Journal. 2008;29(5):625-631. DOI: 10.1093/ eurheartj/ehn011.

[81] Thiele H, Hildebrand L, Schirdewahn C, Eitel I, Adams V, Fuernau G, et al . Impact of high-dose $\mathrm{N}$-acetylcysteine versus placebo on contrast-induced nephropathy and myocardial reperfusion injury in unselected patients with ST-segment elevation myocardial infarction undergoing primary percutaneous coronary intervention. The LIPSIA-N-ACC (Prospective, Single-Blind, Placebo-Controlled, Randomized Leipzig Immediate PercutaneouS Coronary Intervention Acute Myocardial Infarction N-ACC) Trial. Journal of the American College of Cardiology. 2010;55(20):2201-2209. DOI: 10.1016/j.jacc.2009.08.091.

[82] Arstall MA, Yang J, Stafford I, Betts WH, Horowitz JD. N-acetylcysteine in combination with nitroglycerin and streptokinase for the treatment of evolving acute myocardial infarction. Circulation. 1995;92(10):2855-2862. DOI: 10.1161/01.CIR.92.10.2855.

[83] Berenshtein E, Mayer B, Goldberg C, Kitrossky N, Chevion M. Patterns of mobilization of copper and iron following myocardial ischemia: possible predictive criteria for tissue injury. Journal of Molecular and Cellular Cardiology. 1997;29(11):3025-3034. DOI: 10.1006/jmcc.1997.0535.

[84] Voogd A, Sluiter W, van Eijk HG, Koster JF. Low molecular weight iron and the oxygen paradox in isolated rat hearts. Journal of Clinical Investigation. 1992;90(5):2050-2055. DOI: 10.1172/JCI116086.

[85] Funk F, Lenders JP, Crichton RR, Schneider W. Reductive mobilisation of ferritin iron. European Journal of Biochemistry. 1985;152(1):167-172. DOI: 10.1111/j. 1432-1033.1985.tb09177.x.

[86] Biemond P, van Eijk HG, Swaak AJ, Koster JF. Iron mobilization from ferritin by superoxide derived from stimulated polymorphonuclear leukocytes. Possible mecha- 
nism in inflammation diseases. Journal of Clinical Investigation. 1984;73(6):1576-1579. DOI: 10.1172/JCI111364.

[87] Pucheu S, Coudray C, Tresallet N, Favier A, de Leiris J. Effect of iron overload in the isolated ischemic and reperfused rat heart. Cardiovascular Drugs and Therapy. 1993;7(4):701-711. DOI: 10.1007/BF00877824.

[88] Korkmaz S, Barnucz E, Loganathan S, Li S, Radovits T, Hegedus P, et al. Q50, an ironchelating and zinc-complexing agent, improves cardiac function in rat models of ischemia/reperfusion-induced myocardial injury. Circulation Journal. 2013;77(7):18171826. DOI: 10.1253/circj.CJ-12-1162.

[89] van der Kraaij AM, van Eijk HG, Koster JF. Prevention of postischemic cardiac injury by the orally active iron chelator 1,2-dimethyl-3-hydroxy-4-pyridone (L1) and the antioxidant (+)-cyanidanol-3. Circulation. 1989;80(1):158-164. DOI: 10.1161/01.CIR. 80.1.158.

[90] Salonen JT, Nyyssönen K, Korpela H, Tuomilehto J, Seppänen R, Salonen R. High stored iron levels are associated with excess risk of myocardial infarction in eastern Finnish men. Circulation. 1992;86(3):803-811. DOI: 10.1161/01.CIR.86.3.803.

[91] Carr A, Frei B. Does vitamin C act as a pro-oxidant under physiological conditions?. FASEB Journal. 1999;13(9):1007-1024.

[92] Buettner GR, Jurkiewicz BA. Catalytic metals, ascorbate and free radicals: combinations to avoid. Radiation Research. 1996;145(5):532-541.

[93] Buettnera GR, Dohertya TP, Patterson LK. The kinetics of the reaction of superoxide radical with Fe(III) complexes of EDTA, DETAPAC and HEDTA. FEBS Letters. 1983;158(1):143-146. DOI: 10.1016/0014-5793(83)80695-4.

[94] Chatziathanasiou GN, Nikas DN, Katsouras CS, Kazakos ND, Bouba V, Vougiouklakis $\mathrm{T}$, et al. Combined intravenous treatment with ascorbic acid and desferrioxamine to reduce myocardial reperfusion injury in an experimental model resembling the clinical setting of primary PCI. Hellenic Journal of Cardiology. 2012;53(3):195-204.

[95] Karahaliou A, Katsouras C, Koulouras V, Nikas D, Niokou D, Papadopoulos G, et al. Ventricular arrhythmias and antioxidative medication: experimental study. Hellenic Journal of Cardiology. 2008;49(5):320-328.

[96] Williams RE, Zweier JL, Flaherty JT. Treatment with deferoxamine during ischemia improves functional and metabolic recovery and reduces reperfusion-induced oxygen radical generation in rabbit hearts. Circulation. 1991;83(3):1006-1014. DOI: 10.1161/01.CIR.83.3.1006.

[97] Lesnefsky EJ, Repine JE, Horwitz LD. Deferoxamine pretreatment reduces canine infarct size and oxidative injury. Journal of Pharmacology and Experimental Therapeutics. 1990;253(3):1103-1109. 
[98] Reddy BR, Kloner RA, Przyklenk K. Early treatment with deferoxamine limits myocardial ischemic/reperfusion injury. Free Radical Biology \& Medicine. 1989;7(1):45-52. DOI: 10.1016/0891-5849(89)90099-3.

[99] Paraskevaidis IA, Iliodromitis EK, Vlahakos D, Tsiapras DP, Nikolaidis A, Marathias A, et al. Deferoxamine infusion during coronary artery bypass grafting ameliorates lipid peroxidation and protects the myocardium against reperfusion injury: immediate and long-term significance. European Heart Journal. 2005;26(3):263-270. DOI: 10.1093/ eurheartj/ehi028.

[100] Chan W, Taylor AJ, Ellims AH, Lefkovits L, Wong C, Kingwell BA, et al. Effect of iron chelation on myocardial infarct size and oxidative stress in ST-elevation-myocardial infarction. Circulation. Cardiovascular Interventions. 2012;5(2):270-278. DOI: 10.1161/ CIRCINTERVENTIONS.111.966226. 